\title{
PREVENIR, ERRADICAR, COMBATIR VIS $A$ VIS PROMOVER, PROTEGER, GARANTIZAR: LA CONVERGENCIA ENTRE CORRUPCIÓN Y DERECHOS HUMANOS
}

PREVENT, ERADICATE, COMBAT VIS A VIS PROMOTE, PROTECT, GUARANTEE:

THE CONVERGENCE BETWEEN CORRUPTION AND HUMAN RIGHTS

\section{Héctor Guillermo Campbell} Araujo

Profesor-Investigador de tiempo completo. Departamento de Derecho. Universidad de Sonora, México.

Contacto: hector.campbell@unison.mx

(iD https://orcid.org/0000-0001-5293-783X
Rosela de Jesús Rendón Rendón

Profesora-Investigadora de tiempo completo. Departamento de Derecho. Universidad de Sonora, México.

Contacto: roseladejesus.rendon@unison.mx

(iD) https://orcid.org/0000-0001-5334-4470

DOI https://doi.org/10.36796/biolex.v0i23.190

Recibido: 30.10.2020/Aceptado: 20.11.2020

RESUMEN

En presencia de un fenómeno complejo como lo es la corrupción, su definición también lo es. Se le considera como el mal uso o el abuso de un poder delegado para el beneficio propio, es así como la define Transparencia Internacional, el Banco Mundial y la Secretaría de la Función Pública en México, significado orientado hacia el diseño de políticas públicas en materia de eficacia, profesionalización y transparencia de la función pública, por ello es recurrente el identificar corrupción con quien trabaja al servicio del Estado.

Corrupción, derechos humanos.

PALABRAS CLAVES

ABSTRACT

In the presence of a complex phenomenon such as corruption, so is its definition. It is the misuse or abuse of a delegated power for the particular benefit, in these terms it is defined by Transparency International, the World Bank and the Secretariat of the Civil Service in Mexico, a meaning oriented towards the design of public policies in terms of the effectiveness, professionalization and transparency of the civil service, so it is recurrent to identify corruption with those who work in the service of the State.

Corruption, human rights.

KEYWORDS 


Introducción | Metodología | Resultados y
$\begin{aligned} & \text { Discusión | Conclusiones | Referencias } \\ & \text { bibliográficas }\end{aligned}$

\section{Introducción}

$\mathrm{E}$ 1 convencimiento en el individuo de que la o las actividades que debe llevar a cabo no se encuentran regulada o debidamente reguladas, supervisadas y sujetas a rendición de cuentas, tienden a fomentar la corrupción. Lo único que posiblemente lo disuada de realizar estos actos es el miedo a la cárcel, a la multa, el descrédito o la vergüenza social, como lo propuso Glaucón (400 a. C ) $)^{1}$ en su teoría de la naturaleza injusta en todas las personas, al manifestar que sólo son justas por miedo al castigo de la ley o para obtener algún beneficio por su buen comportamiento.

El relato de "El anillo de Giges" dice que el ancestro de Giges el Lidio era un pastor que apacentaba su rebaño en el campo cuando sobrevino una gran tormenta acompañada de un terremoto que abrió una profunda grieta en la tierra, por la que bajó y se sorprendió con las maravillas que le descubría, entre ellas: un caballo de bronce, hueco y un enorme cuerpo sin vida, desnudo, que portaba un anillo de oro y, en ese momento decidió quedarse con él.

El anillo, era mágico, y a voluntad del portador podía volverlo invisible a la vista de los demás. Una vez que el pastor hubo comprobado esta propiedad y consciente del poder adquirido, lo usó para seducir a la reina y, con ayuda de ella, matar al rey, para apoderarse de su reino. ${ }^{2}$

La moraleja señala una realidad universal, atemporal y trascendente que la injusticia es superior a la justicia y, lo que hace el anillo es colocar a su portador fuera del alcance de la justicia, de tal manera que, si fuéramos invisibles como el pastor, seríamos injustos por naturaleza y corruptos irremediablemente.

Dos mil años después, guardando las debidas proporciones, la corrupción sigue siendo tema de relevancia a nivel local, nacional y mundial. Los actores principales son las figuras de políticos y, lo novedoso, de las empresas. De los primeros se asevera que se han aprovechado de sus cargos para obtener beneficios para sí o para terceros. De las Empresas, se sostiene que, en los últimos años, sus actividades que sobrepasan las fronteras nacionales se acompañan de una

\footnotetext{
${ }^{1}$ Lucas Álvarez. "Las figuras del justo y del injusto en República II como antecedentes del sofista y del filósofo en Sofista de Platón”. Nova Tellus 01 (2014): 9-43. http://www.scielo.org.mx/scielo.php?script=sci_arttext\&.pid=S018530582014000200009

${ }^{2}$ Platón. La República. Libro II.
} 
corrupción sin precedentes o "gran corrupción". ${ }^{3}$ Se trivializaría el tema, si consideramos estos dos grandes ejemplos como únicas fuentes, incluso, sería temerario si se asume la perspectiva de ser corruptos irremediablemente.

Los contextos y los factores que dan origen a la corrupción son múltiples, lo que la hace omnipresente y compleja. Sus efectos sobre la persona en su individualidad, así como a la sociedad en general, son extensos y la afectación se sufre en el ámbito económico, social, cultural, ambiental incluso en el derecho al desarrollo de los puebles e impactan a la administración pública y privada, a la estructura humana que labora en ambas esferas y, debilita el Estado de derecho.

De ser corruptos por naturaleza como lo expresó Glaucón, será que nuestro destino es forzoso y, por tanto, ¿debemos acostumbrarnos? En caso contrario, es imperativo continuar en la indagatoria, el análisis de las causas y efectos de la corrupción, en especial la afectación a los derechos humanos de la persona y de la sociedad en su conjunto, para distinguir sus niveles, identificar sus manifestaciones, proponer y llevar a cabo las estrategias adecuadas para su combate, ese es nuestro destino obligado.

\section{Metodología}

Es un estudio descriptivo correlacional, para identificar la problemática vinculada con las acciones que el estado debe llevar a cabo para prevenir, erradicar, combatir la corrupción y la obligación del estado de promover, proteger y garantizar los derechos humanos. Para lo cual se recurrió al método analítico sintético.

\section{¿Somos injustos por naturaleza, proclives a lo ilícito?}

Hace más de dos mil años, Platón, en La República narró la historia de un pastor que encontró un anillo mágico, el anillo de Giges, que le permitió usar el poder de hacerse invisible a voluntad y así, abusando de ese poder cometer toda clase de ilícitos y apropiarse de lo que no le correspondía. El relato sintetiza la esencia más pura de la corrupción: la conducta humana.

Las definiciones que estipulan el concepto así lo confirma, desde la academia, Leff, considera a la corrupción como un conjunto de normas y prácticas extralegales que son usadas por individuos y grupos para ganar influencia en las acciones de la burocracia, es decir, como influencias extralegales en la formulación o implementación de políticas. ${ }^{4}$ Svensson, define a la corrupción

\footnotetext{
${ }^{3}$ Malem, Jorge. Globalización, comercio internacional, corrupción, Barcelona, Gedisa, 2000, p.39.

${ }^{4}$ Leff, Nathaniel, 1964. Economic Development through Bureaucratic Corruption. American Behavorial Scientist. (noviembre): 8 a 14 .
} 
como el mal uso del cargo público con el fin de obtener ganancias privadas. ${ }^{5} \mathrm{La}$ Secretaría de la Función Pública en México hace suya la definición de Transparencia Internacional, que dice "es el abuso del poder para beneficio propio, puede clasificarse en corrupción a gran escala, menor y política, según la cantidad de fondos perdidos y el sector en el que se produzca". ${ }^{6}$ En estas concepciones son claras las referencias al comportamiento humano, voluntario, positivo o negativo, es la persona quien puede realizar la conducta reprochable, positiva o negativa, sea por actividad o inactividad; así como al acto corruptor sobre lo público, sobre el bien público para fines propios. Visibiliza al sujeto corrupto, el individuo investido del poder del Estado, el actor privado que busca un tratamiento favorable y está dispuesto a pagar por ello.

Es la afectación a la persona, a la sociedad en general, lo que analiza Daniel Vázquez el cual manifiesta que los derechos humanos son violentados por la corrupción en varias formas a las que categoriza en cuatro modalidades: la primera, es el acto previo mediante un requerimiento o aceptación de soborno para acceder al goce de un derecho como a la educación, a la salud o el acceso a la justicia entre otros más.

Una segunda relación, es el ofrecimiento u otorgamiento de un soborno para llevar a cabo acciones $\mathrm{u}$ omisiones de cualquier acto en el ejercicio de sus funciones públicas, como puede ser el otorgamiento de permisos de construcción, de una licencia ambiental única (LUA), etc.

La tercera modalidad, la refiere al acto corruptor con efecto sobre los recursos públicos que desmejore o disminuya los servicios públicos, como en el caso de los presupuestos para construcción de hospitales sin partida para equipamiento, la construcción de carreteras con materiales de baja calidad, entre otros.

Finalmente, el incumplimiento a la protección y la garantía al respeto a los derechos humanos como obligaciones del Estado, en lo referente a la estructura organizativa de la procuración y la administración de justicia, así como de sus procesos jurídicos. (Vázquez, 2017)

Lo trascendente es que desde diversas perspectivas buscamos que "el anillo" no funcione, que los actores y los actos corruptos se hagan visibles y audibles, para descubrir a quien o quienes se sienten protegidos por la invisibilidad.

\footnotetext{
${ }^{5}$ Svensson, Jakob. 2005. Eight Questions about Corruption. Journal of Economic Perspectives, 19 (verano): 19 a 42.

${ }^{6}$ Transparency International. “Guía de Lenguaje Claro sobre lucha con la corrupción.” https://transparencia. org.es/wp-content/uploads2014/10/Gu\%C3\%ADa-de-lenguaje-claro-sobre-lucha-contra-la-corrupci\%C3\%B3n.pdf (consultada el 11 de noviembre de 2020).
} 


\section{Desde lo internacional: Los efectos visibles de la corrupción}

La corrupción a lo largo de los más de dos mil años parece un fenómeno consustancial a la humanidad, a la par que ella se desarrolla lo hace también la corrupción, se ha comprobado que deforma las estructuras organizacionales públicas y privadas, violenta los derechos humanos, entorpece el desarrollo de los pueblos, es capaz de desestabilizar la integridad de los sistemas económicos y políticos, destruye la confianza pública en las instituciones de gobierno. A partir de los noventa, ha sido evidente su evolución y su capacidad de traspasar fronteras nacionales, utilizando técnicas especializadas y complejas que hicieron surgir nuevas formas y figuras delictivas en el ámbito público, privado, en el espacio nacional e internacional, afectando a la persona que la sufre y a la comunidad en general que resiente los efectos.

$\mathrm{Al}$ inicio del presente siglo la corrupción no se ha detenido, se ha multiplicado de manera alarmante, adoptando formas cada vez más sofisticada. Es un fenómeno que desplaza una gran cantidad de recursos del Estado y que limita el cumplimiento de sus funciones y la convierte en un gran obstáculo para el desarrollo económico y social que afecta los Derechos Humanos de la población.?

En este escenario, se volvió imperativo buscar nuevas estrategias de enfrentarla mediante el fortalecimiento de la cooperación internacional entre estados, como los primeros obligados en la prevención y erradicación de la corrupción, así como del diseño e implantación de los mecanismos para llevar a cabo las acciones respectivas.

En este sentido, se tomó la experiencia de las Organizaciones internacionales como la OCDE (Organización para la Cooperación y el Desarrollo Económico) que en 1977 impulsó la Convención para combatir el Cohecho de Funcionarios Públicos Extranjeros en Transacciones Comerciales Internacionales, ${ }^{8}$ de la Organización de Estados Americanos (OEA), que expide la Convención Interamericana contra la Corrupción, primer instrumento interamericano que regula los actos de corrupción estatal, que instruye a los estados parte a realizar modificaciones en sus sistemas penales, en lo adjetivo y en lo procesal para establecer los actos de corrupción en los que aplica la Convención y en lo que

\footnotetext{
7 World. Economic Forum. "Los retos de la corrupción en América Latina y cómo enfrentarlos," 2018 https://es.weforum.org/agenda/2018/03/los-retos-de-la-corrupcion-en-america-latina-y-como-enfrentarlos/ (consultada el 11 de noviembre de 2020).

${ }^{8}$ Publicada en el Diario Oficial de la Federación. 27, septiembre de 1999.
} 
respecta a la persecución de estos delitos. ${ }^{9}$ Instrumentos que hicieron visible lo invisible.

En 1993, inició actividades Transparency International (TI), una organización no gubernamental, orientada a informar sobre la corrupción mediante acciones de investigación, de monitoreo al desempeño de los gobiernos y, muy importante, la publicación de los resultados. Es promotora de campañas orientada a corregir las deficiencias en la interacción gobierno- sector privado; desde 1995 publica el índice de percepción de la corrupción y crea dos importantes indicadores, el Índice de Percepción de la Corrupción (IPC) y el Barómetro Global de la Corrupción (BGC), que miden los niveles de percepción de la corrupción por país.

En la misma década la Organización de las Naciones Unidas, asume el liderazgo en la temática, la Asamblea General emitió una serie de resoluciones para definir objetivos y políticas de lucha en contra de la corrupción. Entre ellas, la Resolución A/ES/51/59, "Medidas contra la corrupción" (enero 28,1997); la Resolución A/51/601, "Declaración de Naciones Unidas sobre la corrupción y el soborno en las transacciones comerciales internacionales" (febrero 21, 1997); A/RES/54/128, "Medidas contra la corrupción" (enero 28, 2000). Así como la creación de la Convención de Naciones Unidas contra la Corrupción (2003), instrumento del que México es parte desde su publicación en el Diario oficial de la federación el 14 de diciembre de 2005.

En Europa, en julio 26 de 1995, el Consejo de la Unión Europea, fundamentado en su Tratado de la Unión Europea, aprobó el Convenio relativo a la protección de los intereses financieros de las Comunidades Europeas. En 1999, se firmaron el Convenio de Derecho Penal sobre la Corrupción, auspiciada por el Consejo de Europa (enero 27), y el Convenio de Derecho Civil sobre la Corrupción del Consejo de Europa (noviembre 4).

El siglo XXI, trajo consigo el impulso al cumplimiento de las obligaciones contenidas en las Convenciones por los Estados parte y la adopción de Naciones Unidas de la Convención contra la Corrupción, aprobada en la Resolución 58/4 el 31 de octubre de 2003, suscrita a inicialmente por 95 países, representó la culminación de una labor iniciada muchos años atrás, cuando la palabra "corrupción" apenas se pronunciaba. La Convención, plantea un enfoque amplio respecto de la responsabilidad de prevención y erradicación en los casos de corrupción, que se extiende más allá de los límites estatales, sus objetivos son la

\footnotetext{
${ }^{9}$ Publicada en el Diario oficial de la federación. 9, enero de 1998.
} 
prevención, el fomento a la cooperación internacional, a promover la integridad, rendición de cuentas y la debida gestión de los asuntos y bienes públicos.

Fue necesario hacer esfuerzos sistemáticos — primero de carácter técnico y luego, gradualmente, político- para hacer transitar la lucha contra la corrupción a la agenda mundial. En paralelo, la discusión sobre la centralidad de los derechos humanos y la responsabilidad de su protección por el Estado se fortalecía. ${ }^{10}$

La convergencia entre la lucha contra la corrupción y los derechos humanos, ante sus constantes violaciones, se sitúa en el fortalecimiento del Estado de derecho. En ese sentido el concepto de derechos humanos de acuerdo con la Organización de Naciones Unidas, como "derechos inherentes a todos los seres humanos, sin distinción alguna de raza, sexo, nacionalidad, origen étnico, lengua, religión o cualquier otra condición. Entre los derechos humanos se incluyen el derecho a la vida y a la libertad; a no estar sometido ni a esclavitud ni a torturas; a la libertad de opinión y de expresión; a la educación y al trabajo, entre otros muchos. Estos Derechos corresponden a todas las personas, sin discriminación alguna”. ${ }^{11}$

El costo de un Estado de derecho ausente es notorio en la falta de acceso a la procuración y administración de justicia o la deficiente impartición de justicia, la impunidad de los delitos o los excesos en la aplicación de la ley, los conflictos sociales no atendidos, la inseguridad incluyendo los malos manejos en las Instituciones y Organismos públicos y privados.

La Corte Interamericana de Derechos Humanos (CIDH) en su Resolución 1/17, se refiere a la efectividad de los derechos civiles, políticos, económicos, sociales, culturales y ambientales, a través de la implantación de políticas de eficiencia, profesionalización, transparencia y presupuestos públicos para que el Estado cumpla con su obligación fundamental de promover, proteger y garantizar los derechos humanos de su población y como la corrupción nulifica tal efectividad en especial en tratándose de poblaciones y grupos en condición de mayor vulnerabilidad como las mujeres, los menores, los líderes sociales, defensores del derechos humanos, desplazados forzados, periodistas, pueblos afrodescendientes, los pueblos indígenas, las minorías sexuales, quienes resultan los más afectados. ${ }^{12}$

La reforma al artículo primero de la Constitución Política de los Estados Unidos Mexicanos en el año 2011 ha sido fundamental para todas las autoridades en

\footnotetext{
${ }^{10}$ Publicada en el Diario oficial de la federación. 14, diciembre de 2005.

11 Organización de las Naciones Unidas. ¿Cómo promueve y protege la ONU los derechos humanos? https://www.un.org/es/sections/what-we-do/protect-human-rights/ (consultada el 11 de noviembre de 2020).

${ }^{12}$ Derechos Humanos y Corrupción (CIDH; Resolución 1/18) 02. marzo de 2018; Derechos Humanos y lucha contra la impunidad y la corrupción. (CIDH. Resolución 1/17) 12, septiembre de 2017.
} 
nuestro país, a quienes sin excepción los obliga, en el ámbito de sus competencias, a garantizar efectivamente el goce y disfrute de los derechos humanos de conformidad con los principios de universalidad, interdependencia, indivisibilidad y progresividad. Principios que quedan como elementos básicos de nuestra cultura jurídica actual y criterios de legitimidad del ejercicio del poder público.

Si queremos que estos principios éticos, funcionen en beneficio de todos, es necesario que los intereses, valores e ideales que son su fundamento nos sean comunes, compartidos y asumidos por todos. Lo que requiere de la participación ciudadana, no solo de las autoridades obligadas, para contribuir al respeto, protección y garantía de los derechos humanos que estatuye nuestra Carta Magna, aumentando de este modo la propia integración como sociedad y no solamente la de las autoridades en este proyecto que nos es común. ${ }^{13}$ Rafael De Asís sostiene que la mejor forma de proteger los Derechos Humanos no sólo radica en su planteamiento teórico y dogmático como garantía de los mismos, es absolutamente necesario conocerlos para su realización efectiva y ser capaces de respaldarlos con argumentos consistentes para su fundamentación, delimitación y defensa. ${ }^{14}$

\section{México y su sistema integral contra a la corrupción: Prevenir, erradicar y combatir vis a vis promover, proteger, garantizar y difundir}

Para el año 2005, el sistema jurídico mexicano para la prevención combate, sanción y erradicación de la corrupción, estaba por consolidarse, México es parte de la Convención Interamericana contra la Corrupción, de la Convención para Combatir el Cohecho de Funcionarios Públicos Extranjeros en Transacciones Comerciales Internacionales y de la Convención de las Naciones Unidas contra la Corrupción (CNUC).

Cada uno de estos instrumentos al ser formulado por diversos organismos internacionales, los hace jurídicamente independientes entre sí; no obstante, siendo sus objetivos y fines similares se complementan para constituir un sistema integral para prevenir, erradicar y disuadir las conductas y prácticas públicas y privadas constitutivas de la corrupción. Las obligaciones contenidas en los

\footnotetext{
${ }^{13}$ Ferrajoli. Luigi. Los fundamentos de los derechos fundamentales. (Madrid: Trotta, 2005), 146-147.

${ }^{14}$ De Asís, Roig, Rafael. "Los derechos humanos y discapacidad. Algunas reflexiones derivadas del análisis de la discapacidad desde la teoría de los derechos”, (Madrid: Dykinson -Universidad Carlos III, 2008), 50.
} 
instrumentos internacionales contra la corrupción tienen como destinatario al órgano legislativo de los estados parte.

De acuerdo con el artículo primero de la Convención, las obligaciones que se le asignan son de cinco tipos: Medidas preventivas, tipificación de delitos, normas procesales, normas sobre cooperación internacional y normas sobre recuperación de activos.

Son estas las obligaciones asumidas por el Estado mexicano, en su calidad de Parte de los Tratados en la materia, que debe llevar a cabo hacia el interior y en colaboración con la comunidad internacional signante de todos ellos.

En cumplimiento de sus obligaciones en el 2009, en colaboración con el PNUD (Programa de Naciones Unidas para el Desarrollo) (Programa de Naciones Unidas para el Desarrollo) (Programa de Naciones Unidas para el Desarrollo) se promovió la iniciativa para el Fortalecimiento de la Institucionalidad de los Programas Sociales (IPRO), a través del cual de manera voluntaria las dependencias federales y las correspondientes a las 32 entidades estatales, rinden cuentas de sus programas sociales, mediante informes públicos, neutrales e independientes. Acciones que fomentan la transparencia y la rendición de cuentas. $^{15}$

El 11 de junio de 2012, se publica en el DOF la Ley Federal anticorrupción en contrataciones públicas, el Código Penal federal tipifica las conductas de corrupción de los servidores públicos, se incorporan adiciones en la materia en la Ley de Instituciones de seguros y fianzas. En el año 2015 se expide la Ley Federal de Responsabilidades Administrativas de los Servidores Públicos, en la que se incorporan las estrategias legales para el combate a la corrupción.

Ninguna de ellas, incluso en el contenido de las tres convenciones internacionales que son la estructura del combate a la corrupción refieren como obligación del Estado: la protección y garantía al respeto a los Derechos Humanos de la persona, de todos.

¿Será que somos injustos por naturaleza?, ¿condenados irremediablemente a ser corruptos? Si lo fuéramos, otro sería el panorama. A treinta años de que las organizaciones y organismos internacionales como los nacionales hubieran iniciado acciones para prevenir la corrupción mediante la identificación de sus causas, de llevar a cabo mediciones para identificar niveles, efectos, en cuanto y a

\footnotetext{
${ }^{15}$ Secretaría de Desarrollo Social. Programas Sociales- Transparencia, http://www.sedesol.gob.mx/en/SEDESOL/ Programas_Sociales_Transparencia (consultada el 11 de noviembre de 2020).
} 
quienes afecta, el sistema institucional y el normativo internacional y nacional siguen trabajando arduamente para su erradicación.

\section{Resultados y Discusión La dimensión del problema en México, en datos.}

María Amparo Casar sostiene que la corrupción es condenable por que muestra la falta de ética del binomio gobernante-gobernado y la representa como un hábito cotidiano, normalizada por su práctica diaria en la vida pública y privada. $^{16}$

Para entender el problema, nos referiremos al fundamento de la corrupción: la conducta humana. Conducta que, en el caso de las definiciones de Transparencia Internacional, el Banco Mundial y la Secretaría de la Función Pública en México la refieren tanto a quien ejerce el poder público, como al privado. En ambos casos, es factible identificar un sinnúmero de conductas que una vez que dejan de ser invisibles, pueden ser clasificadas y contabilizadas, de otra manera los actos realizados quedarían fuera del alcance de la justicia, es decir en la impunidad.

\section{Los indicadores Internacionales}

Transparencia Internacional (TI), desde el año 1995, recopila información de 180 países y territorios alrededor del mundo, para identificar el nivel de percepción acerca del sector público, mediante encuestas, a través de sus indicadores IPC y BGC. El primero refleja el mayor o menor grado de corrupción dentro de un parámetro de 0 a 100 , donde cero es altamente corrupto y 100 es el menor grado de corrupción. La posición del estado mexicano en el IPC entre los años 2015 a 2019 nos muestra la Tabla 1.

Tabla 1. Índice de Percepción de la Corrupción. Sector Público. Parámetro: 0 altamente corrupto, 100 menor grado de corrupción

\begin{tabular}{cccccc}
\hline País & 2019 & 2018 & 2017 & 2016 & 2015 \\
\hline México & 29 & 28 & 29 & 30 & 31
\end{tabular}

Elaboración propia. Origen: International Transparency. https://www.transparency.org/en/cpi/2019

\footnotetext{
${ }^{16}$ Casar, María Amparo, México: Anatomía de la Corrupción, Centro de Investigaciones y Docencia Económica CIDE- Instituto Mexicano para la Competitividad A.C. IMCO, México, 2015, p. 39 https://imco.org.mx/wpcontent/uploads/2015/05/2015_Libro_completo_Anatomía_corrupción.pdf
} 
De acuerdo con esta medición México, descendió un punto en el 2018 y de nuevo regresa a la posición 29 en el año 2019. (TI: 2019), que lo ubica entre los últimos lugares de los miembros del Grupo de los 20 (G20), por debajo de países como Argentina o Brasil.

Por otra parte, el BGC, investiga dos indicadores: 1) la percepción sobre las principales instituciones públicas del país; 2) la experiencia directa del ciudadano ante la corrupción referida como victimización. De febrero a marzo de 2019, se aplicó un aproximado de 17,000 encuestas a ciudadanos en 18 países de la región de América Latina y el Caribe, los resultados vertidos en la Tabla 2. Muestran los siguientes datos:

Tabla 2. Barómetro Global de la Corrupción 2019. Resultados para México.

\begin{tabular}{clcc}
\hline \multicolumn{1}{c}{ No. } & \multicolumn{1}{c}{ Indicador } & \multicolumn{2}{c}{ Resultados } \\
& \multicolumn{1}{c}{$\begin{array}{c}\text { Ciudadanos } \\
2019\end{array}$} & $\begin{array}{c}\text { Ciudadanos } \\
2017\end{array}$ \\
\hline 1 & $\begin{array}{l}\text { El nivel de corrupción ha aumentado en su País (actos de } \\
\text { corrupción) }\end{array}$ & $44 \%$ & $61.90 \%$ \\
2 & ¿El nivel de corrupción ha disminuido en su País? & $61 \%$ & $24 \%$ \\
$3 \quad \begin{array}{l}\text { Personas que han sido víctimas de corrupción para acceder } \\
\text { a servicios básicos }\end{array}$ & $34 \%$ & $51 \%$ \\
$4 \quad \begin{array}{l}\text { cEl gobierno en turno maneja bien o muy bien la lucha } \\
\text { contra la corrupción? }\end{array}$ & $61 \%$ & $24 \%$ \\
\hline
\end{tabular}

Elaboración propia. Origen: BGC 2017 y BGC 2019. Trabajo de campo 07.02.2019- 10.03.2019.

Los Indicadores 1., 2. y 4., expresan en porciento lo que percibe la población encuestada. El Indicador 3., hace visible la experiencia de los actores pasivos de la corrupción.

La revisión del trabajo de campo, en referencia al indicador 3., muestra que los mexicanos pagan sobornos a docentes o funcionarios escolares para acceder a servicios de educación, paga a un trabajador o miembro del personal de una clínica u hospitales para acceder a los servicios, a algún funcionario de gobierno para obtener documentos de identidad, o para recibir servicios públicos. Del $21 \%$ al $30 \%$, ha pagado sobornos a la policía para no ser detenido o infraccionado. Del 1 al $10 \%$ ha pagado soborno, alguna dádiva o regalo a un juez o funcionario judicial para acceder a los servicios en la administración de justicia.

$\mathrm{Al}$ hacer la diferenciación por género, el $60 \%$ de hombres y el $59 \%$ de las mujeres están de acuerdo en que socialmente, denunciar la corrupción es aceptable. El $64 \%$ de los jóvenes entre los 18 y 24 años y el $55 \%$ de las personas mayores de 
55 años, se manifestaron de la misma manera: la corrupción es aceptable. Sin embargo, pocos denuncian por temor a represalias. ${ }^{17}$

Existe consenso entre un alto porcentaje de la población en que la corrupción debe denunciarse, sacar a la luz pública al actor y al acto por el cual se sobornó, no obstante, es el temor a la represalia es lo que en un alto porcentaje la inhibe, razón de peso para mantener oculto el hecho.

\section{Los indicadores nacionales}

El Instituto Nacional de Estadística y Geografía INEGI, en marzo de 2020, presentó los "Resultados de la Encuesta Nacional de Calidad e Impacto Gubernamental (ENCIG) 2019”, entre sus indicadores, la denominada Experiencias de Corrupción, apartado en el que se identifican los resultados de la medición sobre percepción y experiencias de corrupción por la población mexicana, correspondiente a los años $2015,2017,2019 .{ }^{18}$ Ver Tabla 3.

Tabla 3. "Tasa de prevalencia de corrupción. Nacional. Por cada 100000 habitantes. Población que experimentó al menos un acto de corrupción al contacto con algún servidor público, al realizar un trámite personal.

\begin{tabular}{|c|c|c|}
\hline \multirow{2}{*}{ Indicador } & \multicolumn{2}{|c|}{ Víctimas } \\
\hline & Año 2019. & Año 2017. \\
\hline Nacional & 15,732 & 14,635 \\
\hline
\end{tabular}

Elaboración: Propia Origen: INEGI. ENCIG (Encuesta Nacional de Calidad e Impacto Gubernamental) 2019.

El Centro Nacional de Información del Secretariado Ejecutivo del Sistema Nacional de Seguridad Pública de la Secretaría de Gobernación, en su "Informe de víctimas de homicidio, secuestro y extorsión 2019”, presenta la incidencia delictiva (presunta ocurrencia) de delitos registrados en averiguaciones previas o carpetas de investigación reportadas por las Procuradurías o Fiscalías estatales y Generales de Justicia en las 32 entidades federativas, del cual se toma lo relativo al Indicador nacional sobre el delito de Extorsión. ${ }^{19}$ Ver tabla 4.

\footnotetext{
${ }^{17}$ Casar, México: Anatomía ... op.cit., p. 25.

18 INEGI. ENGIG 2019 https:/www.inegi.org.mx/contenidos/programas/encig /2019/doc/encig2019_ principales_resultados.pdf (consultada 11 de noviembre, 2020).

${ }^{19}$ Secretariado Ejecutivo del Sistema Nacional de Seguridad Pública, "Informe de víctimas de homicidio, secuestro y extorsión 2015 a 2019, http://secretariadoejecutivo.gob.mx/docs/pdfs/victimas/Victimas2017.pdf. http://secretariadoejecutivo.gob.mx/docs/pdfs/victimas/Victimas2016.pdf.

http:// secretariadoejecutivo.gob.mx/docs/pdfs/victimas/Victimas2015.pdf. (consultado el 11 de_noviembre de 2020).
} 
Tabla 4. "Informe de víctimas de homicidio, secuestro y extorsión" Por cada 100,000 habitantes. Enerodiciembre de 2017 a 2018. Delito Extorsión

\begin{tabular}{lcc}
\hline Indicador & Año 2018 & Año 2017 \\
\hline Nacional & $17.3 \%$ & $19.6 \%$
\end{tabular}

Elaboración: Propia Origen: Centro Nacional de Información del Secretariado Ejecutivo del Sistema Nacional de Seguridad Pública, Secretaria de Gobernación. México.

El informe contiene el registro obtenido en el año 2018 y 2017, dato que relacionamos con el resultado del ENCIG 2017-2019, se toman como referente para dar continuidad a las acciones de combate a la corrupción y a la impunidad existentes. Desde el año 2015 ambos indicadores han sido tomados en consideración en el Sistema Nacional Anticorrupción (SNA), que nace con la reforma constitucional en mayo de 2015, con el propósito de sentar las bases de coordinación entre los tres órdenes de gobierno en materia de prevención, detección y sanción a las faltas administrativas cometidas por los servidores públicos y así lograr mejoras en el quehacer diario del desempeño gubernamental. $^{20}$

El sistema se sustenta en siete leyes reglamentarias aprobadas por el Congreso de la Unión:

1. La Ley General del Sistema Nacional Anticorrupción, sienta las bases de coordinación entre las instituciones que forman el Sistema.

2. La Ley General de Responsabilidades Administrativas, delimita las obligaciones y comportamiento de los funcionarios públicos, así como las sanciones administrativas para quienes incurran en actos de corrupción.

3. La Ley Orgánica del Tribunal Federal de Justicia Administrativa establece el sustrato jurídico para su operación y las sanciones a quienes incurran en faltas administrativas graves.

4. La Ley Orgánica de la Fiscalía General de la República, figura clave del Sistema, pues será la institución encargada de perseguir e investigar actos de corrupción.

5. Adecuaciones a la Ley Orgánica de la Administración Pública Federal que hacen a la Secretaría de la Función Pública responsable del control interno de la administración pública federal.

\footnotetext{
${ }^{20}$ Instituto Nacional de Estadística y Geografía. (2018). "Resultados de la Encuesta Nacional de Calidad e Impacto Gubernamental (ENCIG) 2017",

http://www.beta.inegi.org.mx/contenidos/saladeprensa/boletines/2018/EstSegPub/encig2018_03.pdf (consultado el 11 de noviembre de 2020)
} 
6. Las Adecuaciones al Código Penal que incorporan con suma claridad la tipificación de los delitos de corrupción.

7. Las adecuaciones a la Ley de Fiscalización y Rendición de Cuentas de la Federación que permiten a la ASF (Auditoría Superior de la Federación) (Auditoría Superior de la Federación) fiscalizar recursos públicos en tiempo real, las cuentas públicas de años anteriores, así como las participaciones federales entregadas a las entidades federativas.

La Ley General del Sistema Nacional Anticorrupción se constituye en el instrumento operativo de las nuevas normas, creadas bajo nuevos criterios de denuncia, investigación, sanción, corrección y resarcimiento del daño y las bases para la organización, operación y coordinación del Sistema, ${ }^{21}$ así como la determinación de atribuciones y competencias para diseñar, poner en marcha, evaluar y reportar a la sociedad sobre avances de la política nacional anticorrupción. ${ }^{22}$

A cinco años de la creación del SNA, prevenir, erradicar y combatir la corrupción se tensionan ante el promover, proteger y garantizar los derechos humanos, hoy se dice que a mayor corrupción mayor es el número de quejas ante la Comisión Nacional de Derechos Humanos, entre ellas:

1. Las solicitudes de sobornos como condición de acceso a los derechos (acceso a la justicia o a servicios públicos).

2. El pago de sobornos para llevar a cabo acciones no permitidas y que son violatorias de derechos humanos (obtener evaluaciones de impacto ambiental, evadir medidas de seguridad en la empresa).

3. La disminución de recursos públicos por desvío, adjudicaciones directas de compra de bienes o prestación de servicios).

4. Uso de mecanismos, procesos y lógicas complejas de la corrupción como en el Caso de lava jato ${ }^{23} \mathrm{o}$ el de la constructora Odebrecht ${ }^{24} \mathrm{En}$ todos los casos, la corrupción estructural, endémica sistemática,

\footnotetext{
${ }^{21}$ Que estableció las bases de coordinación, así como las adecuaciones a las leyes conexas relativas a las siete instancias que integran el Sistema: la Auditoría Superior de la Federación (ASF), la Secretaría de la Función Pública, el Tribunal Federal de Justicia Administrativa, el Instituto Nacional de Transparencia, Acceso a la Información y Protección de Datos Personales, la Fiscalía contra la Corrupción, el Consejo de la Judicatura y el Comité de Participación Ciudadana.

${ }^{22}$ Publicada en el DOF, julio 18, 2016.

${ }^{23}$ Mexicanos contra la corrupción y la impunidad, Caso de Lava Jato, https://contralacorrupcion.mx/web/lavajato/ 24 Mexicanos contra la corrupción y la impunidad, La negra historia de Odebretcht en México, https://contralacorrupcion.mx/web/lanegrarelacion/la-negra-historia-de-odebrecht.html
} 
endémica focalizada o aislada son contrarias a los ideales y principios de la Declaración Universal de los Derechos Humanos.

En los contextos que dan origen a la corrupción, se nos muestra omnipresente y compleja. La "Encuesta Nacional de Calidad e Impacto Gubernamental (ENCIG) 2019, que se aplicó de enero a diciembre de 2019, entre una población muestra ubicada en el rango de los 18 años de edad y más, que residen en casas particulares en áreas urbanas con una densidad de población de 100,000 habitantes y más (82 áreas con tal característica con una población estimada de 47.8 millones de personas de 18 años y más), muestra un porcentaje de un $59.2 \%$ con experiencias de corrupción en trámites que involucran a autoridades de seguridad pública; seguido del $25 \%$ en los trámites relacionados con permisos de uso de suelo, demolición o construcción, solicitudes de constancias de libertad de gravamen u otros trámites ante el Registro Público.

Sus efectos sobre la persona en su individualidad, así como en la sociedad en general, son extensos y la afectación se sufre en el ámbito económico, social, cultural, ambiental incluso en el derecho al desarrollo de los puebles. El costo de la corrupción en el período de referencia alcanzó un monto de $\$ 12,770,000,000 \mathrm{mn}$, solo en los casos de contacto con autoridades relacionadas con la vida cotidiana de los hogares, como los son pagos, trámites o solicitudes de servicios públicos y otros servicios.

No obstante, el incremento en el año 2019 en los porcentajes de las diversas experiencias de corrupción, destacan los resultados de la encuesta en el apartado Confianza en las instituciones o actores de la sociedad. El mexicano confía en primer lugar en su familia (87.35), las Universidad de públicas (76.8\%), Escuelas públicas de nivel básico $(74.5 \%)$, Vecinos $(69.8 \%$ ) y en los compañeros de trabajo (68.9\%). Mujeres y hombres, se decantan por confiar más en la familia, los hombres confían más en los vecinos $(71.5 \%)$ y en los compañeros de trabajo $(74.1 \%) .{ }^{25}$ Cada uno de ellos son instancias primarias, en las que la persona adquiere y robustece sus habilidades sociales, sus actitudes y valores para la vida, es decir la esencia de la conducta humana. ${ }^{26}$

¿Las personas comunes pueden hacer una diferencia en la lucha contra la Corrupción? La cuestión que se plantea se relaciona con la conducta humana. Es la "persona común" como promotora de un cambio, la que pretende exhibir al sujeto y al acto corruptor, con la intención de marcar la diferencia en la lucha

\footnotetext{
${ }^{25}$ Los porcentajes decrecen cuando se trata de la confianza en instituciones como el Gobierno federal, estatal, municipal (33.3\%), actores como Jueces y Magistrados (31.7\%), Cámara de Diputados y Senadores (20.6\%) así como los Partidos políticos (17.8\%).

${ }^{26}$ Gauthier, David, La moral por acuerdo, Barcelona, Gedisa, 2000 pp. 26-27.
} 
contra la corrupción. Es la sociedad donde se crean los grupos que promueven los cambios, donde se gestan las propuestas de acciones y estrategias para que sean analizadas y, en su caso, puestas en práctica por las instancias de gobierno.

Si la conducta humana es ser injusta y, por ende, corrupta irremediablemente, la sociedad civil organizada puede mostrar "otros datos". Existe una sociedad organizada o no, pero si interesada, preocupada y trabajando día con día en el diseño de estrategias para hacer frente con mejores prácticas al fenómeno de la corrupción y su impunidad. Existen personas en lo individual que, careciendo de técnicas y metodologías, han logrado crear espacios libres de corrupción.

La conducta humana, es el aporte axiológico al quehacer del individuo, es el factor capaz de analizar, negociar y formalizar los pactos intra e inter-individuos para desarrollar mejores condiciones de vida particulares como de la colectividad en la que se desenvuelve e influenciar a otros mediante acciones colaborativas que pueden ser decisivos para fortalecer las instituciones socializantes primarias (familia, escuela, barrio) y capaces de hacer robustas las instituciones políticas y fortalecer el Estado de derecho.

\section{Conclusiones}

El problema de la corrupción es un tema de gran relevancia a nivel mundial y, en la sociedad mexicana, su arraigo en el ámbito público y privado forman parte de la vida diaria; no llevar a cabo acciones que lo enfrenten tenderá a agravar la situación como lo muestran los diagnósticos y resultados de los Indicadores nacionales e internacionales.

Somos testigo de la disfunción del "Anillo de Giges", ante las acciones emprendidas por el estado mexicano contra políticos corruptos (los exgobernadores detenidos o bajo investigación: Javier Duarte (Veracruz), Guillermo Padres (Sonora), Roberto Borge (Quintana Roo), Tomás Yarrington (Tamaulipas), César Duarte (Chihuahua), Fausto Vallejo (Michoacán), Andrés Granier (Tabasco), Rodrigo Medina (Nuevo León), entre otros.). Las formas corruptas del funcionamiento de instituciones de seguridad o justicia como fue el caso de la desaparición de 5 jóvenes a manos de la Policía estatal y su Comandante en el año 2016. Las acciones de corrupción administrativa, como es el caso de simulación de competencias entre dos empresas, permitiendo que Carlos Peralta y la empresa IUSA (el Rey de los medidores de luz) formalizara contratos con Comisión Federal de Electricidad por 11,833 millones de pesos El caso del malware Pegasus, por medio del cual se dio a conocer la denuncia de espionaje en contra de periodistas, defensores de derechos humanos, de acuerdo 
con el contenido del Informe "Gobierno Espía" realizada por el, periódico The New York Times.

¿Somos injustos por naturaleza? ¿somos proclives a lo ilícito? No resulta fácil responder. Podemos señalar que cada vez las estrategias y técnicas desarrolladas para visibilizar a los actores que corrompen y los actos de corrupción, son más comunes. Entre más informada se encuentre la sociedad mexicana, para identificar y denunciar actos de corrupción, la conducta humana esencia pura de la corrupción, puede reducirse.

Enfrentar el fenómeno de la corrupción requiere conjuntar los esfuerzos de colectivos civiles e instituciones públicas nacionales e internacionales, interesadas y comprometidas en formar un frente común a la corrupción en México.

La creación del Sistema Nacional Anticorrupción y su funcionamiento es un reto para el Estado y la sociedad mexicana. Se requiere el máximo esfuerzo para consolidar la estructura institucional del Sistema; la prevención de actos de corrupción; el combate a la impunidad, y la apertura gubernamental a las propuestas y señalamientos de la sociedad.

\section{Referencias bibliográficas}

Álvarez, Lucas. "Las figuras del justo y del injusto en República II como antecedentes del sofista y del filósofo en Sofista de Platón”. Nova Tellus 01 (2014): 9-43. http://www.scielo.org.mx/scielo.php?script=sci_arttext\&pid=S0185-

30582014000200009

Casar, María Amparo. 2015. Anatomía de la Corrupción. México: Centro de Investigaciones y Docencia Económica CIDE- Instituto Mexicano para la Competitividad A.C. IMCO.

De Asís, Roig, Rafael. 2008. Los derechos humanos y discapacidad. Algunas reflexiones derivadas del análisis de la discapacidad desde la teoría de los derechos, Madrid: Dykinson -Universidad Carlos III.

Ferrajoli. Luis. 2005. Los fundamentos de los derechos fundamentales. Madrid: Trotta. Gauthier, David. 2000. La moral por acuerdo. Ed. Gedisa. Barcelona.

Inegi. Encig 2019. Encuesta Nacional de Calidad e Impacto Gubernamental.

Leff, Nathaniel. 1964. Economic Development through Bureaucratic Corruption. American Behavioral Scientist. Noviembre.

Malem, Jorge. 2000. Globalización, comercio internacional, corrupción. Barcelona: Gedisa. 
Mexicanos contra la corrupción y la impunidad, Caso de Lava Jato, https://contralacorrupcion.mx/web/lavajato/

Mexicanos contra la corrupción y la impunidad, La negra historia de Odebretcht en México, https://contralacorrupcion.mx/web/lanegrarelacion/la-negra-historiade-odebrecht.html

Platón. La república. Libro II.

Rose-Ackerman, Susan. 2010. The Law and Economics of Bribery and Extortion. Annual Review of Law and Social Science.

Svensson, Jakob. 2005. Eight Questions about Corruption. Journal of Economic Perspectives, no. 19 (verano).

Secretariado Ejecutivo del Sistema Nacional de Seguridad Pública, "Informe de víctimas de homicidio, secuestro y extorsión 2015 a 2017.

Transparency International. 2009. Guía de Lenguaje Claro sobre lucha con la corrupción. 